\title{
Detection of difficult calvings in dairy cows using neural classifier
}

\author{
Daniel Zaborski and Wilhelm Grzesiak
}

Laboratory of Biostatistics, Department of Ruminants Science, West Pomeranian University of Technology in Szczecin, Szczecin, Poland

\begin{abstract}
In this study, the detection of dairy cows with difficult calvings using artificial neural networks (ANN) and classification functions (CF) is presented. The set of 15 classification variables was used. The dependent variable was the class of calving difficulty: difficult or easy. Perceptrons with one (MLP1) and two (MLP2) hidden layers as well as radial basis function (RBF) networks were analyzed. The prepared classifiers were characterized by good quality. The accuracy amounted to $75-92 \%$. Only the RBF network had somewhat worse quality. The level of correct detection by ANN was also high. The sensitivity on a test set was $67-80 \%$ at specificity of $61-$ $81 \%$. In the case of CF, a considerable disproportion between sensitivity (6\%) and specificity (99\%) was found. The variables with the greatest contribution to the determination of calving difficulty class were calving season, CYP19-Pvull genotype, pregnancy length and, to a lesser degree, other variables. The performed analyses proved the usefulness of ANN for the detection of cows with difficult calvings, whereas the detection by CF was inaccurate.
\end{abstract}

Keywords: difficult calvings, detection, dairy cows, neural networks, classification functions

\section{Zusammenfassung}

\section{Erkennung schwieriger Abkalbungen bei Milchkühen mittels neuronaler Klassifikatoren}

Die vorliegenden Studie untersucht die Erkennung von Milchkühen mit schwierigen Abkalbungen mittels künstlicher neuronaler Netze (ANN) und Klassifikationsfunktionen (CF). Hierfür wurden 15 Klassifikationsvariablen verwendet. Die Ausgangsvariable war die Schwierigkeitsklasse der Abkalbung: schwierig oder einfach. Analysiert wurden Perzeptronen mit einer (MLP1) und zwei (MLP2) verdeckten Schichten sowie Netze radialer Basisfunktionen (RBF). Die ausgesuchten Klassifikatoren waren durch gute Qualität gekennzeichnet - die Erkennungsrate betrug 75-92\%. Lediglich das RBF-Netz zeigte eine etwas schlechtere Qualität. Die Empfindlichkeitbei einer Testmenge betrug 67-80\%, die Genauigkeit 61-81\%. Im Falle von CF zeichnete sich eine deutliche Disproportion zwischen der Empfindlichkeit (6\%) und der Genauigkeit (99\%) ab. Die Variablen mit der größten Relevanz für die Bestimmung der Schwierigkeitsklasse der Abkalbung waren: Kalbesaison, der Unterschied zwischen der durchschnittlichen Körperkondition und der Körperkondition bei dem Abkalben, der Genotyp CYP19-Pvull, Trächtigkeitsdauer, und im geringeren Maße andere Variablen. Die 
durchgeführten Analysen bestätigten den Nutzen von ANN zur Erkennung von Kühen mit schwierigen Abkalbungen, die Erkennung per CF dagegen war ungenau.

Schlüsselwörter: schwierige Abkalbungen, Erkennung, Milchkühe, neuronale Netze, Klassifikationsfunktionen

\section{Introduction}

Cattle, through the anatomy of their pelvis, are the most predisposed to the occurrence of difficult calvings (dystocia) from among all the species of farm animals. The course of parturition itself is affected by many factors of environmental, anatomical, physiological and genetic nature and at present a large number of genes influencing the quality of calving are known. Among them the oestrogen receptor alpha gene (Szreder \& Zwierzchowski 2004, Szreder et al. 2007) and aromatase cytochrome P450 gene (Vanselow et al. 1999) are mentioned. At the same time, the consequences of difficult calvings go far beyond the necessity of giving direct help by the staff and usually result in considerable economic losses. Therefore, earlier obtaining of information on the potentially difficult calving could be very advantageous to a breeder. Such a possibility is offered by, among others, artificial neural networks (ANN), which can be regarded (or at least some of their types) as artificial intelligence classics (Samarasinghe 2007). ANN have many properties that make them particularly useful for classification and detection tasks. At the same time, they do not require any a priori assumptions concerning e.g. distribution of the analysed variables or the homogeneity of variance. ANN are also insensitive to data errors and capable of capturing complex relationships among variables. Moreover, the prior specification of a model is unnecessary in this case. However, in order to verify the results obtained by means of ANN, a more traditional approach such as discriminant analysis with classification functions (CF) was used in the present study as well. Both CF and ANN have already found many applications in the husbandry and breeding of cattle. Hence, in the present study the detection abilities of the two already classical approaches (from the field of statistics and machine learning) were compared with regard to the detection of cows with difficult calvings. The combined use of the genomic, reproductive and other phenotypic factors for the detection of dystocia in dairy cattle has not been applied so far.

The detailed aims of this study were: 1) to prepare and evaluate the quality of the selected types of ANN and CF used for the determination of the calving difficulty in dairy cows, 2) to evaluate detection of animals with problems at calving by means of selected models and 3) to find which factors had the greatest influence on the course of parturition.

\section{Material and methods}

The research material consisted of 1221 calving records of the Polish Holstein-Friesian cows of the Black-and-White strain (the mean percentage of Holstein-Friesian [HF] genes amounting to $87.73 \%$ ). The calvings occurred between 2004 and 2009. The animals were kept in a loose barn in the West Pomerania Province, where they had access to the outside run over the whole year. The mean $4 \%$ fat-corrected milk (FCM) yield in the analysed period (305-day lactation) 
was $10171 \mathrm{~kg}$. The analysis included only those cows in which no serious diseases before calving were found. The description of the performance parameters is presented in Table 1.

Table 1

Mean values of the analyzed variables (standard deviations in parentheses)

\begin{tabular}{lcrr}
\hline Variable & $\begin{array}{c}\text { Training + validation set } \\
(\mathrm{n}=1016)\end{array}$ & $\begin{array}{r}\text { Test set } \\
(\mathrm{n}=205)\end{array}$ & \multicolumn{1}{c}{$\begin{array}{c}\text { Total } \\
(\mathrm{n}=1221)\end{array}$} \\
\hline \%HF, \% & $87.42(9.33)$ & $86.26(9.05)$ & $87.23(9.29)$ \\
PREG, days & $280(5.90)$ & $280(4.88)$ & $280(5.74)$ \\
BCSI, scores & $0.15(0.33)$ & $0.14(0.33)$ & $0.15(0.33)$ \\
AGE, months & $50.34(11.47)$ & $50.35(11.04)$ & $50.34(11.40)$ \\
CCl, days & $138(54.06)$ & $136(51.50)$ & $137(53.63)$ \\
Cl, days & $412(46.96)$ & $413(51.13)$ & $412(47.67)$ \\
FCM, kg & $10203(2884)$ & $10014(1857)$ & $10171(2739)$ \\
FT_PR\%, \% & $7.61(0.62)$ & $7.57(0.63)$ & $7.60(0.62)$ \\
FIRST_2, kg & $35.06(7.63)$ & $35.35(7.00)$ & $35.11(7.53)$ \\
PEAK, kg & $44.08(8.99)$ & $43.65(7.86)$ & $44.01(8.81)$ \\
LAST_2, kg & $15.06(5.24)$ & $14.38(5.25)$ & $14.94(5.24)$ \\
\hline
\end{tabular}

\%HF: percentage of HF genes in cow genotype, PREG: pregnancy length, BCSI: body condition score index, CCl: calving-to-conception interval, Cl:calving interval, FCM:4\% fat-corrected milk yield, FT_PR\%: combined fat and protein content in milk, FIRST_2: daily milk yield for the first two months of lactation, PEAK: lactation peak milk yield, LAST_2: daily milk yield for the last two months of lactation

For the preparation of individual classifiers the same set of input (classification) variables was used:

$x_{1} \quad[\% H F] \quad$ percentage of HF genes in cow genotype

$\mathrm{x}_{2} \quad[\mathrm{BGLI}] \quad$ oestrogen receptor alpha genotype identified using $B g / l$ restrictase $(E R \mathrm{a}-B g / l)$

$\mathrm{x}_{3} \quad$ [SNA_BI] oestrogen receptor alpha genotype identified using SnaBI restrictase (ERa-SnaBI)

$\mathrm{x}_{4}$ [CYP19] aromatase cytochrome $\mathrm{P} 450$ genotype identified using Pvull restrictase (CYP19-Pvull)

$\mathrm{x}_{5}$ [PREG] pregnancy length (days)

$\mathrm{x}_{6}[\mathrm{BCSI}$ body condition score index (scores)calculated as a difference between the mean $\mathrm{BCS}$ for the previous production season $\left(\mathrm{BCS}_{\mathrm{m}}\right)$ and $\mathrm{BCS}$ at calving $(\mathrm{BCS})$ : $\mathrm{BCSI}=\mathrm{BCS}_{\mathrm{m}}-\mathrm{BCS}$

$x_{7}$ [SEASON] calving season (1: October - May and 2: June - September, according to Klassen et al. 1990)

$\mathrm{x}_{8} \quad[\mathrm{AGE}] \quad$ cow age at calving (months);

$\mathrm{x}_{9} \quad[\mathrm{CCl}] \quad$ calving-to-conception interval (days)

$\mathrm{x}_{10}[\mathrm{Cl}] \quad$ calving interval (days)

$\mathrm{x}_{11}[\mathrm{FCM}] 4 \%$ fat-corrected milk yield $(\mathrm{kg})$, calculated according to the formula: $\mathrm{FCM}=0.4 \cdot \mathrm{ML}+15 \cdot \mathrm{FT}$, where $\mathrm{ML}$ - real milk yield in lactation $(\mathrm{kg}), \mathrm{FT}$ : fat yield $(\mathrm{kg})$

$\mathrm{X}_{12}$ [FT_PR\%] the combined fat and protein content in milk (\%)

$\mathrm{x}_{13}$ [FIRST_2] daily milk yield for the first two months of lactation $(\mathrm{kg})$

$\mathrm{x}_{14}$ [PEAK] daily milk yield at the peak of lactation $(\mathrm{kg})$

$\mathrm{x}_{15}$ [LAST_2] daily milk yield for the last two months of lactation $(\mathrm{kg})$

The body condition of cows was assessed on a 5-point scale (Ferguson et al. 1994). The obtained scores were then modified setting the optimum at 3.50 points and at higher values 
deducting the multiple of 0.25 from 3.50. The cows were assessed at calving (BCS), after calving, during artificial insemination period and during pregnancy $\left(\mathrm{BCS}_{\mathrm{m}}\right)$.

The PCR-RFLP was conducted according to Vanselow et al. (1999), Szreder \& Zwierzchowski (2004) and Szreder et al. (2007). For the $E R a-B g / l$ polymorphism, the $A G$ (3 restriction fragments of 242, 182 and $60 \mathrm{bp}$ ) and GG (2 restriction fragments of 182 and $60 \mathrm{bp}$ ) genotypes were obtained. For the $E R \mathrm{a}-\mathrm{SnaBI}$ polymorphism, the $A A$ (1 restriction fragment of $340 \mathrm{bp}$ without digestion) and $A G$ (3 restriction fragments of 340, 225 and $115 \mathrm{bp}$ ) genotypes were found. Finally, for the CYP19-Pvull polymorphism, the following genotypes were obtained: $A A$ (1 restriction fragment of $405 \mathrm{bp}$ without digestion), $A B$ (3 restriction fragments of 405, 327 and $78 \mathrm{bp}$ ) and $B B$ (2 restriction fragments of 327 and $78 \mathrm{bp}$ ).

The output variable ( $y$ ) was the class of calving difficulty: A - difficult calvings, with a substantial help from man and veterinarian and with potential complications such as placental abruption, stillbirth etc., B - easy calvings, including spontaneous ones or with little help from man. The percentages of calvings from both classes are presented in Figure 1.

The whole set of calving records was randomly divided (Figure 1) into 2 subsets: a set for the preparation of ANN and CF (1016 records) and a test set for the detection of dystocia (205 records). The calvings in the test set were not used either for the building and training of neural models or for the estimation of CF coefficients. In the case of ANN (Figure 1), the set used for their preparation was additionally divided into training set (811 records) and validation set (205 records). This division was based on the proposition of Ivachnenko \& Jurackovskij (1987) but, in the present study, the training set was increased by $16 \%$ in order to provide ANN with more patterns. The validation set was created to monitor the training process, whereas the test set was used for the verification of prediction accuracy. The ANN were built and trained using Statistica Neural Networks software (StatSoft 2000). The best network was selected from among the following types: perceptrons with one hidden layer (MLP1), perceptrons with two hidden layers (MLP2) and radial basis function (RBF) networks. The search for the best network was repeated 10 times each time, which gave a total of 160 ANN for each MLP type and 80 RBF networks.

The quality of the analysed networks was determined using the root mean square (RMS) error for the training and validation sets. The error was calculated according to the following formula (Salehi et al. 1998):

$$
R M S=\sqrt{\frac{\sum_{i=1}^{n}\left(y_{i p r}-y_{i r}\right)^{2}}{n}}
$$

where $y_{i p r}$ is the predicted value of the output variable for the $i$-th calving record, $y_{i r}$ is the real (desired) value of the output variable for the $i$-th calving record and $n$ is the total number of calving records in a given set.

The best network from each category was selected for a detailed analysis. The MLP1 and MLP2 networks were trained with the back-propagation and conjugate gradient methods until reaching the lowest possible RMS error on the validation set. In the training of RBF networks, the basis function centres were selected using k-means clustering, the width parameters were determined by means of the k-nearest neighbour algorithm and the training of the output neuron was performed with the pseudoinversion method (StatSoft 2000). 


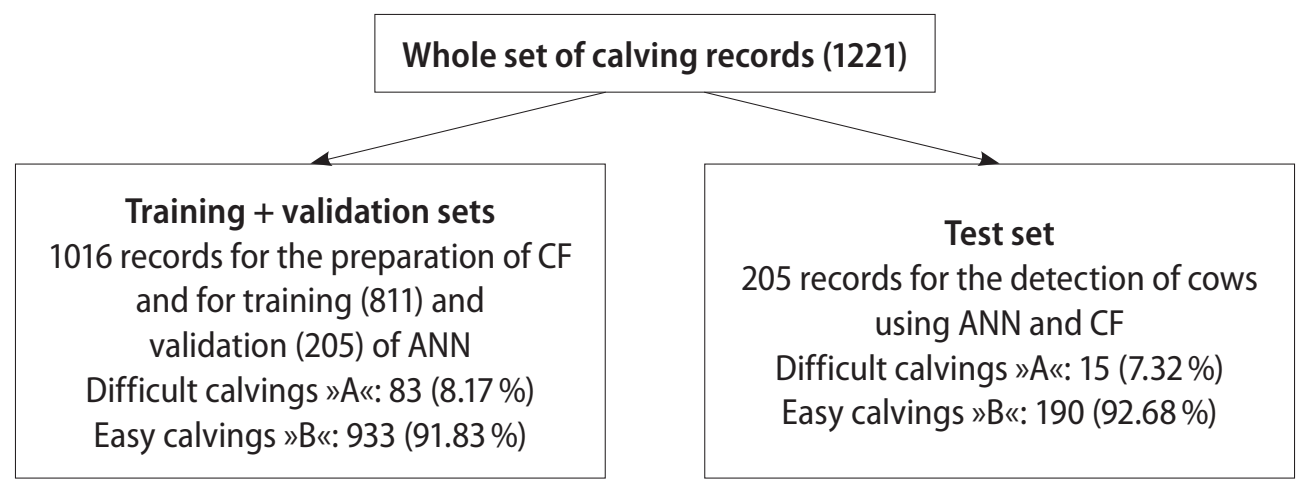

Figure 1

The division of calving records into subsets

For the estimation of the linear CF parameters the following formula was applied:

$$
C F_{k}=w_{k 0}+w_{k 1} X_{1}+w_{k 2} X_{2}+\ldots+w_{k 15} X_{15}
$$

where $C F_{k}$ is the classification function for easy or difficult calvings, $k=1,2, w_{k 0}=\ln q_{k^{\prime}} q_{k}$ probability that a given observation comes from the $k$-th population, $w_{k j}$ is the weight coefficient at the $j$-th original variable, $j=1,2, \ldots, 15$ is the number of classification variable and $x_{1}, x_{2}, \ldots, x_{15}$ are the classification variables.

The value of the classification function, determined for the analysed objects, was compared with the standard, thus assigning the object to a given class. The assumptions of the CF applicability were also verified - the normality of distribution (using the W Shapiro-Wilk test) and homogeneity of variance (Levene's test). The a priori probability was determined proportionally to the size of the groups (Stanisz 2007).

The quality of classification criteria for individual variables was defined using the significance of F statistics calculated on the basis of the Wilks' lambda coefficient (Stanisz 2007):

$$
\Lambda=\prod_{l=i+1}^{p} \frac{1}{1+\lambda_{l}}
$$

where $p$ is the maximum number of discriminant functions, $\lambda_{l}$ is the $l$-th eigenvalue and $i$ is the number of discriminant functions $(i=1,2, \ldots)$.

The quality of the classification results by individual models was determined by means of sensitivity - conditional true positive probability and specificity - conditional true negative probability:

$$
\text { Sensitivity }=\frac{A}{A+C} \quad \text { Specificity }=\frac{D}{B+D}
$$

where $A$ is the number of correctly detected difficult calvings, $B$ is the number of easy calvings misclassified as difficult ones, $C$ is the number of difficult calvings misclassified as easy ones and $D$ is the number of correctly detected easy calvings. 
Additionally, the probability of true positive and true negative response, also known as accuracy, was calculated:

$$
\text { Accuracy }=\frac{A+D}{A+B+C+D}
$$

The differences between probabilities were calculated for the training and validation sets together (the same was applied to the estimation of CF parameters) using a two-proportion test for unequal variances.

When comparing the quality of the analysed models, Akaike information criterion (AIC; Akaike 1974), which is a measure describing the goodness of fit, was also determined. The model with the lowest AIC value was selected. The criterion was calculated according to the following formula (Liddle 2007):

$$
A I C=X^{2}+2 d+\frac{2 d(d+1)}{n-d-1} \quad X^{2}=\sum_{k=1}^{c} \frac{\left(n_{k}-o_{k}\right)^{2}}{n_{k}}
$$

where $c$ is the number of the observed classes, $n_{k}$ is the number of records assigned to class $k$ by a model, $o_{k}$ is the number of observations in class $k, d$ is the number of model parameters and $n$ is the number of observations.

After preparation and evaluation of the ANN and CF quality on the basis of the training and validation sets, the ability of individual models to detect cows with dystocia was verified on the basis of the test set. For the evaluation of detection performance, the aforementioned probabilities as well as receiver operating characteristic (ROC) curves and area under these curves (AUC) were used. The ROC curves enabled to visually compare the detection performance of the analysed classifiers, whereas the AUC values indicated the discrimination power of the models (Fawcett 2004).

In the last stage of the study, the input variables that had the greatest influence on the determination of calving difficulty class were identified. To do this, the ANN sensitivity analysis was performed. The measure was the ratio coefficient (the higher the value the more significant the variable) and rang, which ordered the variables according to decreasing error. In the case of CF, the contribution of variables was defined using the tolerance coefficient $\mathrm{T}$ (Grzesiak et al. 2010).

\section{Results}

Based on the lowest RMS error for the validation set, the ANN types presented in Table 2 were selected for further analyses.

In the case of CF, all the explanatory variables except FT_PR\% were characterized by the deviation from the normal distribution. The assumption concerning the homogeneity of variance was not fulfiled either ( $\mathrm{AGE}, \mathrm{Cl}$ and $\mathrm{FCM}$ variables). It should be emphasized that the fulfilment of these assumptions is not required when using ANN. The differences in the quality of the classifiers become visible when analysing the probabilities calculated for the training and validation sets (Table 3).

ANN were characterized by the greater ability to detect cows with difficult calvings compared with CF. However, CF almost perfectly identified individuals without calving 
difficulties, although the level of these indications for ANN was also high and similar to the sensitivity values. Only the RBF network was characterized by somewhat lower level of correct indications of cows from both categories. Accuracy of indications of cows from both distinguished classes was again greater for CF.

The AIC values calculated on the basis of the training and validation sets were: 117.99 (MLP1), 116.44 (MLP2), 328.54 (RBF) and 409.68 (CF).

Table 2

The structure of artificial neural networks (ANN) and the root mean square (RMS) error for ANN and classification functions (training and validation sets)

\begin{tabular}{lrl}
\hline Type of classifier & Structure & RMS \\
\hline Perceptron with one hidden layer & $17-12-1$ & 0.23 \\
Perceptron with two hidden layers & $17-12-8-1$ & 0.22 \\
Radial basis function network & $17-4-1$ & 0.27 \\
Classification functions & - & 0.25 \\
\hline
\end{tabular}

Structure: number of neurons in the input, hidden and output layers, respectively

Table 3

The values of individual probabilities for artificial neural networks and classification functions

\begin{tabular}{lrlll}
\hline Set & $\mathrm{n}$ & Sensitivity & Specificity & Accuracy \\
\hline Perceptron with one hidden layer & & & & \\
$\quad$ Training + validation & 1016 & $0.7470^{\mathrm{AB}}$ & $0.7492^{\mathrm{AB}}$ & $0.7490^{\mathrm{AB}}$ \\
$\quad$ Test & 205 & $0.8000^{\mathrm{AB}}$ & $0.8053^{\mathrm{AB}}$ & $0.8049^{\mathrm{AB}}$ \\
$\begin{array}{l}\text { Perceptron with two hidden layers } \\
\quad\end{array}$ & 1016 & $0.7590^{\mathrm{CD}}$ & $0.7503^{\mathrm{CD}}$ & $0.7510^{\mathrm{CD}}$ \\
$\quad$ Training + validation & 205 & $0.7333^{\mathrm{C}}$ & $0.7789^{\mathrm{CD}}$ & $0.7756^{\mathrm{CD}}$ \\
$\quad$ Test & & & & \\
Radial basis function network & 1016 & $0.5783^{\mathrm{ACE}}$ & $0.5874^{\mathrm{ACE}}$ & $0.5866^{\mathrm{ACE}}$ \\
$\quad$ Training + validation & 205 & $0.6667^{\mathrm{AD}}$ & $0.6105^{\mathrm{ACE}}$ & $0.6146^{\mathrm{ACE}}$ \\
$\quad$ Test & & & & \\
Classification functions & 1016 & $0.1566^{\mathrm{BDE}}$ & $0.9850^{\mathrm{BDE}}$ & $0.9173^{\mathrm{BDE}}$ \\
$\quad$ Training + validation & 205 & $0.0667^{\mathrm{BCD}}$ & $0.9947^{\mathrm{BDE}}$ & $0.9268^{\mathrm{BDE}}$ \\
$\quad$ Test & & & & \\
\hline
\end{tabular}

$A, B, C, D, E P \leq 0.01$

The prepared ANN and CF were then used for the detection of difficult calvings on the basis of the test set, which comprised information on the new calvings not presented previously either to the ANN or CF. A general trend in the values of the individual probabilities on the training and validation sets remained on the test set (Table 3). ANN were characterized by a high and similar percentage of correct detection of cows with difficult and easy calvings. Only the RBF network showed lower level of sensitivity and specificity, whereas for CF, the disproportion between the detection of individuals with difficult and easy calvings was observed, to the disadvantage of the former. The highest accuracy was exhibited by CF.

The AUC value indicating the discrimination power of the model (Figure 2), determined on the basis of the test set, was the highest for MLP1 and the lowest for the RBF network.

In the last stage of the study, the variables with the significant contribution to the determination of calving difficulty class were indicated. The sequence of these variables is given in Table 4. 

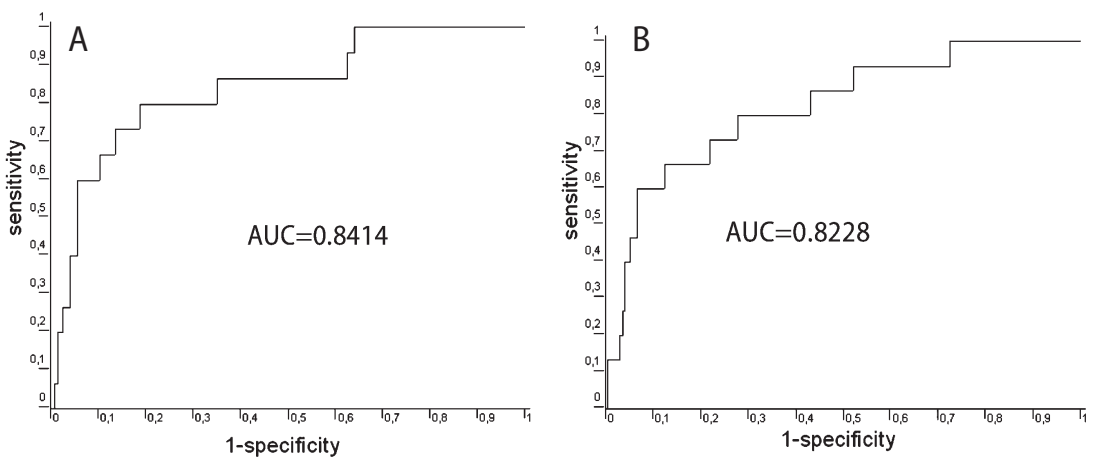

A: using the perceptron with one hidden layer (MLP1)

B: using the perceptron with two hidden layers (MLP2)
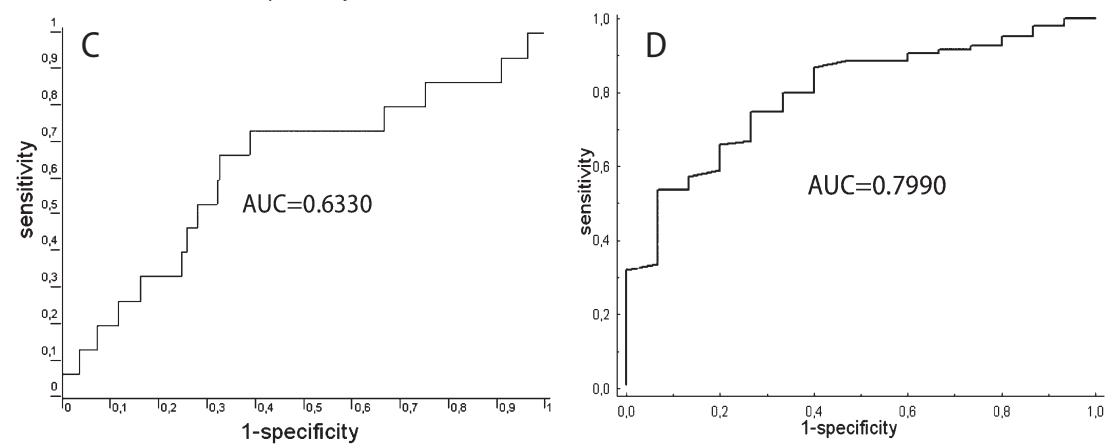

C: using the radial basis function (RBF) network D: using the classification functions (CF)

Figure 2

Receiver operating characteristic (ROC) curves and area under curve (AUC) values for the detection of difficult calvings

Table 4

The sequence of variables according to their contribution to the determination of calving difficulty class

\begin{tabular}{lcccccccc}
\hline Variable & \multicolumn{2}{c}{ MLP1 } & \multicolumn{2}{c}{ MLP2 } & \multicolumn{2}{c}{ RBF } & \multicolumn{2}{c}{ CF } \\
& Ratio & Rang & Ratio & Rang & Ratio & Rang & T & Rang \\
\hline \%HF & 1.0254 & 9 & 1.1002 & 4 & 1.0001 & 5 & 0.9317 & 5 \\
BGLI & 1.0034 & 14 & 1.0001 & 15 & 1.0004 & 3 & 0.4638 & 11 \\
SNA_BI & 1.0146 & 11 & 1.0134 & 14 & 1.0004 & 4 & 0.4650 & 10 \\
CYP19 & 1.0876 & 4 & 1.0998 & 5 & 1.0102 & 1 & $0.9760^{* *}$ & 1 \\
PREG & 1.0679 & 5 & 1.1005 & 3 & 1.0000 & 9 & $0.9546^{* *}$ & 4 \\
BCSI & 1.0896 & 3 & 1.1056 & 2 & 0.9999 & 12 & $0.9646^{* *}$ & 2 \\
SEASON & 1.1070 & 1 & 1.1449 & 1 & 1.0061 & 2 & $0.9614^{* *}$ & 3 \\
AGE & 1.0171 & 10 & 1.0848 & 6 & 0.9997 & 14 & 0.5386 & 9 \\
CCI & 1.0317 & 7 & 1.0585 & 10 & 0.9999 & 13 & 0.2123 & 13 \\
CI & 1.0009 & 15 & 1.0164 & 12 & 0.9994 & 15 & 0.2126 & 12 \\
FCM & 1.0082 & 13 & 1.0158 & 13 & 1.0000 & 8 & 0.5498 & 8 \\
FT_PR\% & 1.0130 & 12 & 1.0292 & 11 & 1.0000 & 10 & $0.8602^{*}$ & 6 \\
FIRST_2 & 1.0654 & 6 & 1.0586 & 9 & 1.0000 & 7 & $0.1842^{* *}$ & 15 \\
PEAK & 1.0937 & 2 & 1.0755 & 7 & 1.0000 & 11 & $0.1958^{* *}$ & 14 \\
LAST_2 & 1.0288 & 8 & 1.0733 & 8 & 1.0000 & 6 & $0.7358^{*}$ & 7 \\
\hline
\end{tabular}

MLP1: perceptron with one hidden layer, MLP2: perceptron with two hidden layers, RBF: radial basis function network, CF: classification functions, T: tolerance coefficient, ${ }^{*} P \leq 0.05,{ }^{* *} P \leq 0.01$; statistical significance concerns the $\mathrm{F}$ statistics, \%HF: percentage of HF genes in cow genotype, BGLI: ERa-Bgll genotype, SNA_BI:ERa-SnaBI genotype, CYP19:CYP19Pvull genotype, PREG: pregnancy length, BCSI: body condition score index, CCl: calving-to-conception interval, Cl: calving interval, FCM: $4 \%$ fat-corrected milk yield, FT_PR\%: combined fat and protein content in milk, FIRST_2: daily milk yield for the first two months of lactation, PEAK: lactation peak milk yield, LAST_2: daily milk yield for the last two months of lactation 


\section{Discussion}

As it can be seen from Table 2, the RMS error for the analysed classifiers was low (below 0.3), which testifies to the good quality of the analysed models (StatSoft 2000). The non-fulfilment of the assumptions concerning the normal distribution of variables and homogeneity of variance can be tolerated at greater sample sizes (Stanisz 2007). However, it does not remain without influence on the results of classification by means of CF. When using CF, one should also take into account the collinearity which, in spite of including modified explanatory variables in this study, may always appear.

The accuracy calculated on the basis of the training and validation sets was in general similar to that obtained by other authors. Morrison et al. (1985a, b) applying discriminant analysis to the prediction of dystocia in beef cattle obtained the percentage of correct classifications equal to $82-85 \%$, whereas Basarab et al. (1993) obtained the values in the range $85-89 \%$. Montgomery et al. (1987) investigating mastitis detection in cows by means of discriminant analysis obtained the coefficient of correct classification amounting to 0.78 .

The applied goodness-of-fit criterion (AIC) allowed us to conclude that the best quality was exhibited by the MLP2 network.

When discussing the individual probabilities defining the quality of detection, it should be first emphasized that the rate of indication of cows with difficult calvings, that is, sensitivity is definitely more important for the breeder than the effectiveness of indicating cows with easy calvings, that is, specificity. The misclassification of a cow with calving difficulty is not as dangerous as indication of cow that will not have such problems, which can »dull« breeder's vigilance. In this respect, CF did not turn out to be useful in practice and the higher probability of indicating an animal with problems can be obtained in a purely random manner. In the studies concerning the application of ANN the sensitivity was, in general, high and similar to that obtained in the present work. In the research on mastitis detection it ranged from 0.24 (Yang et al. 1999) to 0.93 (Cavero et al. 2008). In the study on the oestrus detection in cows (Krieter et al. 2006) sensitivity amounted to 0.78 , whereas in the lameness detection in cattle (Pastell \& Kujala 2007) $100 \%$ of cows were correctly diagnosed. In the studies on the application of discriminant analysis the level of sensitivity amounted to 0.05-0.32 (Basarab et al. 1993), 0.39 (Montgomery et al. 1987) and 0.57 (Morrison et al. 1985b), so it was relatively low and similar to the values for $\mathrm{CF}$ in the present study.

Specificity obtained in this research for ANN was lower than that in the studies by Yang et al. (1999) and Yang et al. (2000), where it amounted to $0.83-1.00$ and $0.67-0.85$, respectively. In other studies on mastitis detection these values ranged from 0.38 (Cavero et al. 2008) to 1.00 (Nielen et al. 1995, Wang \& Samarasinghe 2005). In the study by Krieter et al. (2006) the percentage of correctly classified cows without oestrus was $100 \%$, whereas Pastell \& Kujala (2007) obtained the percentage of correctly indicated cows without lameness amounting to $58 \%$. For discriminant analysis, specificity was 0.90 (Morrison et al. 1985b), 0.91 (Montgomery et al. 1987) and 0.73-0.99 (Basarab et al. 1993). The specificity obtained in the present study was in general similar to the aforementioned values, which proves certain »carefulness" of the neural classifiers in the indication of classes comprising animals without calving problems, mastitis or lameness, whereas the strictly statistical methods did not show such "carefulness", which is disadvantageous from the breeder's point of view. 
Accuracy given in the literature was in a similar range as that obtained in the present work and was not lower than 50\%. For example, in the study by Yang et al. (1999) these values amounted to $0.62-0.99$ and in the work by Yang et al. (2000) they ranged from 0.55 to 0.78. Pastell \& Kujala (2007) and Morrison et al. (1985b) obtained accuracy of 0.96 and 0.84 respectively. According to Basarab et al. (1993), 68-93\% of heifers were correctly diagnosed, whereas Montgomery et al. (1987) studying mastitis detection by means of discriminant analysis obtained the maximum accuracy on the test set of 0.75 .

Based on the AUC values for the test set, it can be concluded that the greatest discrimination power was exhibited by MLP1. In the study by Yang et al. (1999) the AUC values were somewhat higher and ranged from 0.77 to 0.87 , whereas in the study by Pastell \& Kujala (2007) this value was 0.86 , indicating the high ability of the model to discriminate between healthy and lame cows.

In the last stage of the research, classification variables that had the greatest influence on the determination of calving difficulty class were indicated (Table 4). The most significant variable was SEASON. According to Meijering (1984), in our climatic zone, higher percentage of dystocia cases can be observed in autumn and early winter, which may be caused by less intensive supervision of cows by farmers during the spring-summer season. An easier access to pasture in summer, higher level of physical exercises and longer days are additional factors favouring easy calvings (Zaborski et al. 2009). The next important variable was BCSI, which is a difference between the mean body condition and condition at calving. Both too low and too high body condition at calving has an adverse influence on the course of parturition (the optimum BCS is regarded as 3.25-3.75 points on a 5-point BCS scale; Zaborski et al. 2009). Roche et al. (2009) stated that there is an association between the changes of body condition in cows during the periconceptional period and the size of calf and its sex at subsequent calving. Since greater calf size and the male sex are positively correlated with calving difficulty, the BCS change during the early stage of gestation may have connection with the difficulty of the next calving. Also, too high condition during the dry period prolongs gestation, increases the foetus weight and favours difficult calvings (Czerniawska-Piątkowska et al. 2005). Moreover, cows of a higher BCS at calving have more intrapelvic fat reserves and thus decreased pelvic area, which may be associated with dystocia (Avendaño-Reyes et al. 2010).

Also, the CYP19-Pvull genotype (CYP19 variable) played an important part in the determination of the course of calving. The CYP19 gene codes for an enzyme (aromatase cytochrome P450), which catalyses a key step in oestrogens biosynthesis. Their increased level during the antepartum period has a significant influence on the late gestation and calving (Fürbass et al. 2010). In ruminants, a decreased level of oestrogens and their reduced secretion just before parturition are associated with an increased risk of abortion, retained placenta and dystocia (Fürbass et al. 2010). In cows with difficult calvings, caused by incomplete dilatation of the cervix, the level of oestrogens was significantly lower than that in the individuals without calving difficulties (Janowski \& Zduńczyk 1995). However, the effect of the two remaining genotypes (ERa-Bgll and $E R a-S n a B I)$ was smaller. The PREG variable had a high value of ratio coefficient either. Meijering (1984) showed that gestation length was phenotypically correlated with difficult calvings and that their more frequent occurrence was associated with longer gestation. Also, shorter than normal gestation may cause dystocia as stated by Niskanen \& Juga (1997), who justified this by indicating that calves are then smaller and weaker. 
The $\% \mathrm{HF}$ was the next variable of high significance. In general, the improvement of the Blackand-White cattle using the semen of Holstein bulls, conducted in Poland resulted in the increased occurrence of difficult calvings compared with the individuals of the pure Blackand-White breed (Trela et al. 1996). Also, in the world, the increasing proportion of genes of the Holstein breed originating in North America in the genotypes of Friesian cows in Sweden, Denmark, Great Britain, Israel, Ireland, and of Jersey cows in Australia affects calving difficulty resulting in greater birth weight and longer gestation (Mee 2008). For perceptrons, the PEAK and AGE variables were also quite important. However, it is difficult to explain connection between the first of these two variables and dystocia, since most studies on this subject have not shown such relationship (Erb et al. 1981, 1985, Martin et al. 1982, Curtis et al. 1985, Erb 1987). An effect of the two other variables associated with milk yield (FIRST_2 and LAST_2) was smaller, whereas in the case of age at calving, it is known that younger cows usually have more difficult calvings irrespective of the number of parturitions and that the age of cows is directly related to their body size and indirectly to the size of their calves (Zaborski et al. 2009). The sequence of remaining variables varied depending on the classifier used.

The tolerance coefficient values and the significance of $F$ statistics in the case of CF confirmed, in general, the results of ANN sensitivity analysis; although one more variable related to yield (FT_PR\%) appeared to be significant for CF.

It should be emphasized that all the diagnostic variables except for genotypes were obtained from the data bases of herd management software. Only acquiring information on the genotypes can be problematic in the breeding practice at present. However, taking into account a relatively low cost of genotyping per one individual in relation to the considerable financial losses associated with dystocia, it can be expected that such analyses will become more popular in the near future. According to the results obtained in the present study, the determination of CYP19-Pvull genotype is sufficient because the effect of the two remaining genotypes on dystocia detection was smaller.

Based on the performed research, it can be concluded that the individual types of ANN used for the classification of calving difficulty in dairy cows were characterized by high quality. Also, the detection of individuals with dystocia performed by means of ANN was effective, whereas the usefulness of CF in this respect was dubious. The variables with the greatest contribution to the determination of the calving difficulty class were: SEASON, PREG, CYP19, BCSI,\%HF, PEAK and AGE. Due to the significance of the BCSI variable, it can be suggested that breeders assess body condition in order to obtain additional indicator in dystocia detection in cattle using neural classifier.

\section{References}

Akaike H (1974) A new look at the statistical model identification. IEEE T Automat Contr AC-19, 716-723

Avendaño-Reyes L, Fuquay JW, Moore RB, Liu Z, Clark BL, Vierhout C (2010) Relationship between accumulated heat stress during the dry period, body condition score, and reproduction parameters of Holstein cows in tropical conditions. Trop Anim Health Pro 42, 265-273

Basarab JA, Rutter LM, Day PA (1993) The efficacy of predicting dystocia in yearling beef heifers: II. Using discriminant analysis. J Anim Sci 71, 1372-1380

Cavero D, Tölle KH, Henze C, Buxadé C, Krieter J (2008) Mastitis detection in dairy cows by application of neural networks. Livest Sci 114, 280-286 
Curtis CR, Erb HN, Sniffen CJ, Smith RD, Kronfeld DS (1985) Path analysis of dry period nutrition, postpartum metabolic and reproductive disorders, and mastitis in Holstein cows. J Dairy Sci 68, 2347-2360

Czerniawska-Piątkowska E, Bernd L, Kamieniecki H, Wójcik J, Rzewucka E, Żychlińska-Buczek J (2005) Condition of dairy cows and its effect on fertility. Wiad Zoot 43, 3-8 [in Polish]

Erb HN (1987) Interrelationships among Production and Clinical Disease in Dairy Cattle: A Review. Can Vet J 28, 326-329

Erb HN, Martin SW, Ison N, Swaminathan S (1981) Interrelationships between production and reproductive diseases in Holstein cows. Path analysis. J Dairy Sci 64, 282-289

Erb HN, Smith RD, Oltenacu PA, Guard CL, Hillman RB, Powers PA, Smith MC, White ME (1985) Path model of reproductive disorders and performance, milk fever, mastitis, milk yield, and culling in Holstein cows. J Dairy Sci 68, 3337-3349

Fawcett T (2004) ROC graphs: Notes and practical considerations for researchers. Technical Report HPL-20034. HP Labs, Palo Alto, CA, USA http://home.comcast.net/ tom.fawcett/public_html/papers/ROC101.pdf [last accessed 22.09.2011]

Ferguson JD, Galligan DT, Thomsen N (1994) Principal descriptors of body condition in Holstein dairy cattle. J Dairy Sci 77, 2695-2703

Fürbass R, Tomek W, Vanselow J (2010) Upstream Stimulating Factors 1 and 2 Enhance Transcription from the Placenta-Specific Promoter 1.1 of the Bovine Cyp19 Gene. BMC Mol Biol 11, 5-13

Grzesiak W, Zaborski D, Sablik P, Żukiewicz A, Dybus A, Szatkowska I (2010) Detection of cows with insemination problems using selected classification models. Comput Electron Agr 74, 265-273

Ivachnenko ZB, Jurackovskij AG (1987) Simulation of complex systems from experimental data. Radio and Communications, Moscow [in Russian]

Janowski T, Zduńczyk S (1995) The present view on the oestrogens synthesis in placenta and their role in hormonal regulation of calvings. Med Weter 51, 578-80 [in Polish]

Klassen DJ, Cue RI, Hayes JF (1990) Estimation of repeatability of calving ease in Canadian Holsteins. J Dairy Sci 73, 205-212

Krieter J, Stamer E, Junge W (2006) Control charts and neural networks for oestrus dectection in dairy cows. Lecture Notes in Informatics. Land- und Ernährungswirtschaft im Wandel - Aufgaben und Herausforderungen für die Agrar- und Umweltinformatik, Referate der 26. GIL Jahrestagung, 06.-08. März 2006, Potsdam, Deuschland,133-136

Liddle AR (2007) Information criteria for astrophysical model selection. Mon Not R Astron Soc, Letters 377, L74-78

Martin SW, Aziz SA, Sandals WCD, Curtis RA (1982) The association between clinical disease, production and culling of Holstein-Friesian cows. Can J Anim Sci 62, 633-640

Mee JF (2008) Prevalence and risk factors for dystocia in dairy cattle: A review. Vet J 176, 93-101

Meijering A (1984) Dystocia and stillbirth in cattle - A review of causes, relations and implications. Livest Prod Sci 11, 143-177

Montgomery ME, White ME, Martin SW (1987) A comparison of discriminant analysis and logistic regression for the prediction of coliform mastitis in dairy cows. Can J Vet Res 51, 495-498

Morrison DG, Humes PE, Keith NK, Godke RA (1985a) Discriminant analysis for predicting dystocia in beef cattle. I. Comparison with regression analysis. J Anim Sci 60, 608-616

Morrison DG, Humes PE, Keith NK, Godke RA (1985b) Discriminant analysis for predicting dystocia in beef cattle. II. Derivation and validation of a prebreeding prediction model. J Anim Sci 60, 617-621

Nielen M, Spigt MH, Schukken YH, Deluyker HA, Maatje K, Brand A (1995) Application of a neural network to analyse on-line milking parlour data for the detection of clinical mastitis in dairy cows. Prev Vet Med 22, $15-28$

Niskanen S, Juga J (1997) Calving difficulties and calf mortality in Finnish dairy cattle population. Interbull Bull 18, 17-20 
Pastell ME, Kujala M (2007) A probabilistic neural network model for lameness detection. J Dairy Sci 90, 22832292

Roche JR, Friggens NC, Kay JK, Fisher MW, Stafford KJ, Berry DP (2009) Invited review: Body condition score and its association with dairy cow productivity, health, and welfare. J Dairy Sci 92, 5769-5801

Salehi F, Lacroix R, Wade KM (1998) Improving dairy yield predictions through combined record classifiers and specialized artificial neural networks. Comput Electron Agr 20, 199-213

Samarasinghe S (2007) Neural Networks for Applied Science and Engineering. From Fundamentals to Complex Pattern Recognition. Auerbach Publications, Boca Raton, New York, USA

Stanisz A (2007) An accessible statistics course using Statistica PL with examples from medicine. Vol. II. Linear and non-linear models. StatSoft Cracow, Poland, 53, 66-68, 108-109 [in Polish]

StatSoft (2000) Statistica Neural Networks. Program guide. StatSoft Inc., Tulsa, OK, USA

Szreder T, Zwierzchowski L (2004) Polymorphism within the bovine estrogen receptor-a gene 5'-region. J Appl Genet 45, 225-236

Szreder T, Żelazowska B, Zwierzchowski L, Pareek CS (2007) A novel nucleotide sequence polymorphism in the $5^{\prime}$-noncoding region of bovine estrogen receptor a gene, the RFLP-SnaBI. Biochem Genet 45, 255-262

Trela J, Kasińska K, Soukup T, Grzegorzewski S, Wójcik P, Adamik A (1996) Using bulls of the German variety to improve Black-and-White cattle in the region of Gdansk. Conference »Cattle breeding in Poland: history and future $149-157$ [in Polish]

Vanselow J, Kühn C, Fürbass R, Schwerin M (1999) Three PCR/RFLPs identified in the promoter region 1.1 of the bovine aromatase gene (CYP19). Anim Genet 30, 232-233

Wang E, Samarasinghe S (2005) On-Line Detection of Mastitis in Dairy Herds Using Artificial Neural Networks. In:Zerger A, Argent RM (eds) MODSIM 2005 International Congress on Modelling and Simulation. Modelling and Simulation Society of Australia and New Zealand, December 2005, 273-278

Yang XZ, Lacroix R, Wade KM (1999) Neural detection of mastitis from dairy herd improvement records. TASAE 42, 1063-1071

Yang XZ, Lacroix R, Wade KM (2000) Investigation into the production and conformation traits associated with clinical mastitis using artificial neural networks. Can J Anim Sci 80, 415-426

Zaborski D, Grzesiak W, Szatkowska I, Dybus A, Muszyńska M, Jędrzejczak M (2009) Factors affecting dystocia in cattle. Reprod Domest Anim 44, 540-551

Received 16 November 2010, accepted 21 April 2011.

Corresponding author:

Daniel Zaborski

email: daniel.zaborski@zut.edu.pl

Laboratory of Biostatistics, Department of Ruminants Science, West Pomeranian University of Technology in Szczecin, Doktora Judyma 10, 71-460 Szczecin, Poland 